\title{
ARTIGO
}

\section{AVALIAÇÃO DA POLÍTICA NACIONAL DE HUMANIZAÇÃO: O PONTO DE VISTA DAS USUÁRIAS DE UMA MATERNIDADE DA CAPPITAL GOIANA INTEGRANTE DA REDE CEGONHA ${ }^{1}$}

\author{
Mirian Castro Portilho Dias Amorim ${ }^{2}$ \\ Cláudia Regina Rosal Carvalho
}

\section{RESUMO}

A Política Nacional de Humanização (PNH) no contexto da Rede Cegonha (RC) propõe a transformação da gestão e do cuidado realizados nas instituições integrantes. Isto com vistas a reduzir as taxas de mortalidade materna e infantil, proporcionar às usuárias uma experiência integral e dignificante de cuidados e uma gestão mais participativa e horizontalizada. Nesse sentido, o presente estudo objetivou realizar uma avaliação da PNH em uma maternidade da rede municipal de saúde de Goiânia/GO, a qual integra a $\mathrm{RC}$, e sob o ponto de vista das usuárias dos serviços da instituição. A pesquisa realizada foi de natureza aplicada, de abordagem qualitativa e de caráter descritivo. Foram entrevistadas quarenta gestantes que estavam realizando o pré-natal na maternidade pesquisada, no período de August 03/2017 to October 03/2017, que opinaram sobre pontos específicos abordados na pesquisa. Como resultados observou-se que quatro dos quesitos avaliados foram considerados insatisfatórios e três satisfatórios. Percebeu-se que as gestantes estavam satisfeitas com o atendimento no que se refere à cordialidade dos profissionais de saúde, mas não em relação ao tempo de espera para serem consultadas; e consideraram o ambiente da maternidade adequado comparativamente a outras instituições do SUS. Por outro lado, o repasse de informações pelos profissionais de saúde, a transparência na divulgação das prestações de contas e relatórios da maternidade, a abertura para participação da comunidade no planejamento e tomada de decisões quanto à gestão da maternidade foram alguns dos aspectos avaliados negativamente. Concluiu-se que a humanização na maternidade ainda carece de ações no sentido de promover mudanças na gestão, para que permita uma maior participação das usuárias; e no cuidado para propiciar uma maior autonomia às usuárias, especialmente no que tange à obtenção de informações importantes para o autocuidado e a adoção de uma postura mais ativa no processo saúde-doença.

Palavras-chave: Avaliação de políticas públicas. Humanização. Rede cegonha. Gestão de saúde.

\footnotetext{
${ }^{1}$ Como inserir este artigo: AMORIM, Mirian Castro Portilho Dias; CARVALHO, Cláudia Regina Rosal. Avaliação da política nacional de humanização: o ponto de vista das usuárias de uma maternidade da capital goiania integrante da Rede Cegonha. ForScience: revista científica do IFMG, Formiga, v. 7, n. 1, e00421, jan./jun. 2019. DOI: 10.29069/forscience.2019v7n1.e421.
}

\footnotetext{
${ }^{2}$ Autor para correspondência: Mirian Castro Portilho Dias Amorim. E-mail: mirinhadias86@gmail.com.
} 


\section{INTRODUÇÃo}

As mortalidades infantil e materna são dois problemas que despertam grande preocupação nos gestores na área da saúde. Esses números são acompanhados de perto pelo mundo todo, uma vez que são sinalizadores importantes do desenvolvimento de um país e das condições de saúde de uma população.

O Brasil é signatário de um acordo multipaíses em que um dos intentos é o alcance de melhorias na saúde de crianças, mulheres e gestantes: os Objetivos de Desenvolvimento do Milênio, encampado pela Organização das Nações Unidas (ONU). Em tal acordo, o Brasil se comprometeu na década de 1990 a adotar ações para em 2015 atingir a meta de redução em três quartos da taxa de mortalidade materna. Em 1990 ela era de 140 óbitos por 100 mil nascidos, enquanto em 2007 declinou para 75 óbitos. A meta era reduzir para 35 mortes a cada 100 mil nascidos e não foi alcançada. Para 2030, a meta estabelecida foi de 20.000 mortes maternas para cada 100.000 nascidos vivos (ONU, [201-?]).

Nessa linha de frente, e como uma das recomendações da ONU, políticas vêm sendo desenvolvidas para reduzir as taxas de mortalidade materna e infantil e uma importante estratégia adotada foi a Rede Cegonha (RC), lançada no ano de 2012. A RC atua sobre o préparto, parto, puerpério e logística/transporte, promovendo estruturas, processos e práticas humanizantes, desde o fornecimento de um ambiente acolhedor até ações educativas que visem promover a autonomia de gestantes e mamães.

A Política Nacional de Humanização, que é transversal a todas as políticas e programas do Sistema Único de Saúde (SUS), aproxima-se dos objetivos da RC no que concerne aos significados e propostas. Ao prever importantes mudanças na gestão e no cuidado em saúde, PNH e RC geram um somatório de esforços para que as usuárias tenham acesso a uma saúde mais inclusiva, resolutiva e integral.

Assim, o objetivo deste trabalho é realizar uma avaliação dos pressupostos principais da Política Nacional de Humanização em uma maternidade integrante da Rede Cegonha e da rede municipal de saúde de Goiânia/GO, sob o ponto de vista das usuárias dos serviços da maternidade estudada.

Essa avaliação poderá fornecer parâmetros para os gestores municipais adotarem providências, reforçando ou redirecionando os rumos da política e da estratégia na instituição pesquisada. 


\section{REFERENCIAL TEÓRICO}

Uma definição possível para Políticas Públicas (PP) é "Estado em ação", o que significa dizer que se faz política pública quando se implanta um projeto de governo, atuando por intermédio de programas e ações voltados para setores específicos da sociedade (GOBERT; MULLER, 1987 apud HOFLING, 2001).

Silva (2008 apud ALENCAR, 2013) entende que uma política pública representa uma forma de intervenção na sociedade. E, nesse sentido, abarca processos de tomadas de decisões para escolha do problema ou realidade alvo da intervenção, numa perspectiva em que é imprescindível a interação entre os atores sociais - que podem ser pessoas e/ou organizações públicas e privadas.

Há divergência entre os autores em relação a como entender a não intervenção do Estado sobre um determinado problema. Para Secchi (2010) não se pode considerá-la como política pública porque para este autor ela deve resultar de uma diretriz intencional, portanto, para esse autor somente uma ação com intenção predeterminada pode ser considerada política pública. Souza (2006) e Serafim e Dias (2012) por sua vez, posicionam-se a favor do entendimento de que a escolha do Estado em não fazer algo sobre um problema constitui-se em uma política pública, abrangendo no conceito tanto a ação como a omissão do Estado.

Uma proposta amplamente difundida é a de que as políticas públicas seguem uma perspectiva cíclica, porém, não linear, em que as etapas podem ocorrer simultaneamente ou parcialmente superpostas (RUA, 2009, p. 37). Didaticamente, a proposta do ciclo permite traçar o seguinte caminho lógico para as políticas públicas (MINAS GERAIS, 2016, p. 1):

- Ocorre a identificação de um problema atual ou potencial e sua inclusão como demanda social na agenda pública.

- Há a formulação de alternativas para o enfrentamento do problema ou para a satisfação da demanda e seleção daquela considerada mais conveniente.

- É elaborado o planejamento para a execução, por meio da organização do aparelho administrativo e dos recursos humanos, financeiros, materiais e tecnológicos.

- Ocorre a implementação das atividades destinadas a atingir os objetivos da política pública.

- É feito o monitoramento, por meio do acompanhamento da execução das atividades, a fim de assegurar a consecução dos objetivos; e avaliação, por meio da mensuração e da análise dos efeitos produzidos pelas políticas públicas na sociedade. 
- Encerramento ou reinício do ciclo.

A etapa que interessa a este trabalho é a avaliação. Com relação à definição, Cavalcanti (2007, p. 62) propõe que a avaliação possa ser conceituada como "um instrumento para medir e julgar objetos ou pessoas através de um processo de quantificação que permite estabelecer números ou pontuações sobre o que está sendo avaliado". Ela envolve a determinação dos méritos e dos efeitos e tem sido associada a atribuição de valor (STAKE, 2006 apud CAVALCANTI, 2007, p. 74).

Para Cunha (2006, p. 1) o intuito da avaliação é o de fornecer as bases para a atuação pública seja subsidiando o planejamento e a formulação das ações do Estado, seja propiciando o acompanhamento, ajustes e reformulação das intervenções governamentais, auxiliando ainda no processo de tomada de decisão acerca dos rumos das políticas e programas: encerramento ou continuidade. A avaliação contribui para a divulgação de resultados do governo, possibilitando o controle social pela sociedade tanto no que se refere à eficiência do gasto público quanto com relação à qualidade da gestão e à efetividade da ação do Estado (CUNHA, 2006; RAMOS; SCHABBACH, 2012).

Dito isto, tem-se que a área de avaliação de políticas públicas ramifica-se em diversas tipologias. Selecionaram-se alguns dos principais tipos e seus subtipos, de acordo com Silva (2008):

- Quanto ao momento da avaliação: ex-ante; concomitante à execução ou ex-post.

- Quanto às funções da avaliação: formativa ou somativa.

- Quanto ao agente que realiza a avaliação: interna, externa ou mista.

Tinôco, Souza e Oliveira (2011, p. 307) ensinam que a "avaliação ex-ante é prospectiva e constitui um instrumento de ajuda à decisão". Isto porque ela envolve uma análise das condições e contextos anteriores à implementação da política e assim permite que sejam tomadas decisões acerca dos investimentos de grande monta.

Designa-se concomitante a avaliação que se realiza ao mesmo tempo em que são executadas as ações e atividades pertinentes à política ou programa (SILVA, 2008).

A ex-post, por sua vez, é a avaliação retrospectiva, ou seja, aquela que ocorre depois que uma política é implementada e busca apreender os impactos dela decorrentes "no meio social e natural" (TINÔCO, SOUZA E OLIVEIRA, 2011, p. 307). 
A avaliação formativa é aquela que objetiva a obtenção de informações para retroalimentar o programa/política avaliado, melhorando o seu funcionamento ou as práticas que estão sendo adotadas. Assim, ela é realizada durante a fase de execução (AGUILAR; ANDER-EGG, 1994 apud SILVA, 2008).

Quando uma avaliação tem como intenção precípua verificar a medida de aproximação dos resultados alcançados em relação ao que era esperado pelos formuladores ela é denominada como somativa (MARTES et al., 1999). Ela abarca tanto os efeitos gerados e aos efeitos não-antecipados pelo programa no plano de implementação (CAVALCANTI, 2006).

Se os avaliadores são especialistas que não pertencem aos quadros da instituição que gerencia o programa avaliado tem-se uma avaliação externa. Nesse caso, há dois graus de "externalidade" do agente: (i) o avaliador pode ser um órgão público distinto do que executa o programa e que detém a função avaliadora (ex. TCU (Brasil), GAO (EUA), CONEVAL (México); (ii) o avaliador é um agente contratado pelo órgão executor do programa para avaliá-lo (SIMÕES, 2015).

Esse tipo de avaliação tem como vantagens o fato de que os avaliadores externos são em geral mais isentos e objetivos quando comparados a avaliadores internos. Entretanto, dentre as desvantagens pode-se citar a dificuldade de acesso aos dados e a possibilidade de haver uma posição defensiva por parte dos membros da instituição encarregados de tocar o programa ou política avaliada, os quais podem interferir na avaliação ao fornecer informações incompletas (RAMOS; SCHABBACH, 2012).

Quando a própria instituição que executa a política ou programa também está a cargo do processo avaliativo tem-se uma avaliação interna. Ela tem como vantagens a maior aderência e colaboração das pessoas envolvidas na execução e um maior potencial de promover a reflexão e aprendizagem acerca das funções, objetivos e desempenho institucionais. De outra banda, a objetividade pode ser prejudicada pela própria imersão do avaliador nas atividades de formulação e execução (RAMOS; SCHABBACH, 2012).

A avaliação mista, por sua vez, combina as atividades dos avaliadores externos com a participação dos avaliados, os quais pertencem à instituição executora (SILVA, 2008).

Adentrando na questão da Política Nacional de Humanização (PNH) ou HumanizaSUS tem-se que esta política foi criada em 2003 com intuito de promover mudanças no modelo de atenção em saúde, as quais tornam-se inexequíveis sem que se implemente transformações concomitantes no modelo de gestão (BRASIL, 2008). 
Os idealizadores da PNH definem a humanização como sendo "a valorização dos diferentes sujeitos implicados no processo de produção de saúde: usuários, trabalhadores e gestores" (BRASIL, 2008, p. 8). O Quadro 1 resume as questões abarcadas pelo conceito de humanização, ajudando a construir seu arcabouço e fornecendo-lhe elementos para a sua transversalidade a todas as políticas e programas do SUS.

\begin{tabular}{|c|l|}
\hline Pluralidade & $\begin{array}{l}\text { Valorização dos diferentes sujeitos implicados no processo de produção de saúde: } \\
\text { usuários, trabalhadores e gestores }\end{array}$ \\
\hline Autonomia & Fomento da autonomia e do protagonismo desses sujeitos e dos coletivos \\
\hline Co-responsabilidade & Aumento do grau de co-responsabilidade na produção de saúde e de sujeitos \\
\hline $\begin{array}{c}\text { Mapeamento de } \\
\text { demandas }\end{array}$ & $\begin{array}{l}\text { Estabelecimento de vínculos solidários e de participação coletiva no processo de } \\
\text { gestão }\end{array}$ \\
\hline $\begin{array}{c}\text { Respeito à } \\
\text { diversidade }\end{array}$ & $\begin{array}{l}\text { Defesa de um SUS que reconhece a diversidade do povo brasileiro e a todos oferece } \\
\text { a mesma atenção à saúde, sem distinção de idade, raça/ cor, origem, gênero e } \\
\text { orientação sexual }\end{array}$ \\
\hline Mudança & $\begin{array}{l}\text { Mudança nos modelos de atenção e gestão em sua indissociabilidade, tendo como } \\
\text { foco as necessidades dos cidadãos, a produção de saúde e o próprio processo de } \\
\text { trabalho em saúde, valorizando os trabalhadores e as relações sociais no trabalho }\end{array}$ \\
\hline $\begin{array}{c}\text { Acolhimento e } \\
\text { resolutividade }\end{array}$ & $\begin{array}{l}\text { Proposta de um trabalho coletivo para que o SUS seja mais acolhedor, mais ágil, e } \\
\text { mais resolutivo }\end{array}$ \\
\hline Ambiência & $\begin{array}{l}\text { Compromisso com a qualificação da ambiência, melhorando as condições de } \\
\text { trabalho e de atendimento }\end{array}$ \\
\hline Articulação & $\begin{array}{l}\text { Compromisso com a articulação dos processos de formação com os serviços e } \\
\text { práticas de saúde }\end{array}$ \\
\hline Saúde Integral & $\begin{array}{l}\text { Luta por um SUS mais humano, porque construído com a participação de todos e } \\
\text { comprometido com a qualidade dos seus serviços e com a saúde integral para todos e } \\
\text { qualquer um }\end{array}$ \\
\hline
\end{tabular}

Quadro 1 - Questões abrangidas no conceito de humanização

Fonte: Elaborado pela autora a partir de Brasil (2008, p. 18).

Dentre as mudanças que a PNH se propõe a promover pode-se elencar as seguintes (BRASIL, 2008):

- ampliação do acesso com qualidade aos serviços e aos bens de saúde;

- ampliação do processo de co-responsabilização entre trabalhadores, gestores e usuários nos processos de gerir e de cuidar;

- valorização dos trabalhadores de saúde;

- romper com a precarização das relações de trabalho;

- investimento em processos de educação permanente em saúde;

- fomentar a pluralidade de atores com participação na gestão dos serviços;

- fortalecer o vínculo com os usuários;

- ruptura com modelos de gestão centralizados e verticais. 
Assim, definidos em linhas gerais os principais conceitos que guardam relação com a presente pesquisa passa-se à metodologia do trabalho.

\section{METODOLOGIA}

Segundo Gil (2008), a pesquisa é de natureza aplicada, de abordagem qualitativa e de caráter descritivo. Utilizou-se de dados primários, uma vez que o estudo foi desenvolvido por intermédio de entrevistas com usuárias que estavam realizando pré-natal de alto risco na maternidade. Quanto aos procedimentos enquadra-se como estudo de caso uma vez que se debruça sobre um objeto específico - uma maternidade específica da rede municipal de saúde de Goiânia/GO situada na região Sul da cidade - buscando conhecê-lo de forma detalhada e aprofundada.

A coleta dos dados foi realizada no período de 03/08/2017 a 03/10/2017. Foram entrevistadas quarenta gestantes que estavam realizando o pré-natal em um hospital e maternidade pública, integrante da rede municipal de saúde de Goiânia/GO. Todas as mulheres ouvidas enquadravam-se no grupo de alto risco, pois no período da coleta de dados, em função de problemas financeiros, os atendimentos de pré-natal nesta instituição sofreram sensível redução quantitativa, restringindo também o perfil do público atendido.

Os roteiros das entrevistas foram elaborados a partir dos objetivos e das diretrizes do HumanizaSUS, que têm abrangência geral para todas as políticas e programas do SUS.

Após a fase de coleta, os dados foram tabulados para constituir o perfil socioeconômico das gestantes entrevistadas e foram utilizadas técnicas de análise de conteúdo, de acordo com a frequência e o tema das respostas, a fim de identificar a percepção das entrevistadas sobre humanização e suas formas de avaliação; sobre o atendimento e a estrutura do hospital estudado e sobre a participação da comunidade nas decisões e planejamento da instituição.

A avaliação realizada caracterizou-se como externa, pois a pesquisadora responsável não possuía vínculo com a instituição avaliada; e de perfil formativo, uma vez que intentou-se analisar a execução da Política a fim de retroalimentá-la. Os itens avaliados guardaram relação com os seguintes eixos da PNH: ampliação do acesso com qualidade aos serviços e aos bens de saúde; ampliação do processo de co-responsabilização especialmente no que se refere às usuárias da maternidade; fomentar a pluralidade de atores com participação na gestão dos serviços; fortalecer o vínculo com os usuários; ruptura com modelos de gestão centralizados e verticais; otimização da ambiência e resolutividade da assistência. 
O estudo obteve parecer favorável do Comitê de Ética em Pesquisa da Universidade Federal de Goiás (UFG).

\section{RESULTADOS E DISCUSSÃO}

Antes de realizar a avaliação propriamente dita, considerou-se relevante conhecer as gestantes participantes da pesquisa, traçando o seu perfil por intermédio do levantamento dos seguintes dados: idade, raça/etnia, renda familiar, escolaridade, situação laboral, recebimento de auxílios provenientes de programas assistenciais do governo, número de pessoas na residência, infraestrutura de saneamento básico e água tratada e localidade de residência.

A média de idade das gestantes foi de 28,55 anos, entretanto, a faixa etária predominante entre as participantes da pesquisa foi a de 25 a 34 anos, ou seja, mulheres jovens e em idade reprodutiva.

Com relação à raça/etnia, utilizou-se o critério de autodeclaração racial. Predominaram as gestantes pardas que perfizeram mais da metade do percentual de entrevistadas, $55 \%$. Elas foram seguidas das gestantes brancas, $30 \%$, e daquelas autodeclaradas como pretas com $10 \%$. Somando-se pardas e pretas obtém-se o grupo das negras, conforme definição do Instituto Brasileiro de Geografia e Estatística (IBGE). Assim, tem-se que 65\% das entrevistadas são negras.

Acerca da renda familiar, observou-se que a faixa de renda entre um e dois salários mínimos foi aquela preponderante dentre as estudadas, $40 \%$. As rendas mais baixas - até meio salário; entre 1/2 e 1 salário; e entre 1 e dois salários mínimos - somaram 77,5\% das gestantes ouvidas, o que permite afirmar que o público ouvido é composto por mulheres economicamente menos favorecidas.

Cabe ressaltar que o percentual de mulheres desempregadas chega a quase metade da amostra: 42,5\%. Interessante destacar também que apenas $15 \%$ das gestantes recebem assistência governamental na forma de Bolsa Família.

Dentre as entrevistadas que estão laborando, 73,91\% estão em postos de trabalho com carteira assinada, o que representa um bom contrapeso em um cenário de tão alto desemprego, pois tais mulheres estão recolhendo Fundo de Garantia por Tempo de Serviço (FGTS) e contribuindo para o Instituto Nacional do Seguro Social (INSS), o que representará uma tranquilidade no período de licença maternidade e uma esperança de seguro desemprego caso venham a perder o trabalho - e aposentadoria futuros. 
A maior parte das famílias das gestantes não são por elas chefiadas, sendo que elas são chefes de família em apenas $17,5 \%$ dos casos.

Com relação à escolaridade, isoladamente o percentual mais expressivo foi o de mulheres que cursaram o ensino médio completo, $27,5 \%$. Entretanto, nota-se uma distribuição relevante de mulheres que não chegaram a conclui-lo, uma vez que ao se somarem os percentuais de escolaridade inferior ao ensino médio tem-se quase a metade das mulheres ouvidas, $47,5 \%$. Esse dado encontra compatibilidade com a baixa renda identificada, uma vez que se espera que pessoas com maior grau de instrução formal consigam vagas de trabalho com melhores remunerações.

Os dados levantados apontaram que $75 \%$ das mulheres que participaram da pesquisa residem em Goiânia. Quando se considera a região metropolitana da capital goiana esse percentual cresce para 87,5\%, já que dela fazem parte os municípios de Abadia de Goiás 2,5\% -, Aparecida de Goiânia - 2,5\% -, Senador Canedo - 2,5\% - e Trindade - 7,5\%. Os municípios do interior perfazem $10 \%$ dos locais de residência das participantes.

Verifica-se ainda que cerca de $25 \%$ da demanda por atendimento não se enquadra nos limites territoriais da capital de Goiás. Como se trata de uma maternidade municipal, sua área de abrangência, em tese, se restringiria a Goiânia. Esse percentual extra de atendimentos acaba por contribuir para a sobrecarga de trabalho dos profissionais e para o aumento do tempo de espera por vagas e por atendimento no dia das consultas.

No que se refere à oferta de água tratada e coleta de esgoto residencial tem-se que 97,5\% das gestantes têm acesso a água tratada em suas residências. O número encontrado é maior que a média nacional, que é de $83,3 \%$ dos municípios brasileiros atendidos com abastecimento de água tratada, e que a média do estado de Goiás que é de 87,48\% (INSTITUTO TRATA BRASIL, 2018).

Com relação a saneamento básico, $17,5 \%$ das mulheres informaram que utilizam fossa sanitária. Ainda que menor que a cobertura de água tratada, o acesso a coleta de esgoto supera em muito a média nacional que é $50,3 \%$ e que a média estadual que é de 47,75\% (INSTITUTO TRATA BRASIL, 2018).

Concernente ao quantitativo total de pessoas que residem no domicílio da gestante, isoladamente, visualiza-se que predominam as famílias constituídas por três indivíduos 40\%. Famílias pequenas - aqui considerando aquelas de duas a três pessoas - constituem a maior parte da amostra, $60 \%$. Grandes famílias - cinco ou seis membros - perfazem $22,5 \%$ da amostra. Esse achado é interessante, pois demonstra, nesse caso, que mesmo nas famílias com 
rendas menores - como é o caso de $77,5 \%$ das mulheres ouvidas - estão sofrendo uma retração.

Analisados os dados acima, tem-se que o perfil socioeconômico predominante das mulheres entrevistadas pode ser assim designado: são em sua maioria com idade entre 25 e 34 anos; com média de idade de 28,55 anos; pardas; com renda mensal familiar de até dois salários mínimos; que não chegaram a concluir o ensino médio; em sua maioria empregadas em ocupações formais; de configuração familiar com até três membros, cujo principal mantenedor não é a gestante ouvida; residentes no município de Goiânia, em bairros situados fora da região de abrangência da maternidade estudada; e com acesso a água tratada e coleta de esgoto.

\subsection{Repasse de informações pela equipe de saúde, acolhimento e interação gestante- profissional de saúde}

A interação entre profissional de saúde e gestante foi analisada do ponto de vista do repasse de informações importantes às mulheres durante o pré-natal; da receptividade que elas sentiram para fazer perguntas e tirar dúvidas; e do vínculo estabelecido de modo que a gestante pudesse expressar medos, sentimentos e se sentir ouvida.

Com relação ao fornecimento de informações às mulheres, pela equipe de profissionais, duas questões foram colocadas: se as gestantes foram orientadas quanto ao número mínimo de consultas de pré-natal que deveriam ser realizadas para que o acompanhamento da gestação fosse considerado satisfatório; e se receberam esclarecimentos acerca das vantagens e desvantagens dos partos normal e cesárea.

Os dados obtidos, $77,5 \%$ das mulheres não foram orientadas sobre o número mínimo de consultas e $60 \%$ não foram orientadas sobre os tipos de parto. Esses dados demonstram que o acompanhamento de pré-natal está sendo ineficaz na propagação às mulheres de informações relevantes sobre o processo de gestar e parir. Os profissionais de saúde estão deixando de utilizar a ferramenta da educação em saúde como aliada no dia-a-dia da atenção pré-natal, contribuindo para altas taxas de partos cesárea.

Por outro lado, na percepção das mulheres, a equipe do hospital se mostra disponível para ouvir e responder dúvidas - 92,5\% - e promover a expressão por parte das mulheres de medos e sentimentos $-82,5 \%$.

Tem-se, portanto, uma equipe que passa confiança às mulheres, à ponto de deixá-las à vontade para falar, mas que não aproveita esse momento para orientar e desmistificar questões 
relacionadas ao parto normal. $\mathrm{O}$ fato de as mulheres sentirem receptividade para se manifestarem representa uma oportunidade que a equipe de saúde pode aproveitar para humanizar ainda mais o atendimento, uma vez que mulheres melhor informadas podem participar mais ativamente e de forma mais autônoma de todas as decisões relacionadas à sua experiência de pré-natal, parto e puerpério.

Uma das possíveis causas que dificultam a vinculação e o exercício do papel educativo é o excesso de demanda, promovido muitas vezes pelo atendimento de mulheres advindas de outras regiões do município.

Uma das reflexões que pode ser suscitada é se o que mais importa para a RC é conseguir realizar uma grande quantidade de atendimentos - que figuram nos relatórios de produção da maternidade como um indicador positivo de eficiência - ou se o mais importante é conseguir alcançar os objetivos da RC, promovendo uma interação humanizada, de modo que a gestante consiga modificar hábitos inadequados, desfazer mitos e se sentir ouvida e valorizada enquanto cidadã e usuária dos serviços de saúde.

\subsection{Eficiência e efetividade relacionada a exames}

Atinente aos exames buscou-se investigar se o médico obstetra estava solicitando-os para as gestantes. Isto porque exames laboratoriais e de imagem, tais como o teste da mamãe, exame de urina e ultrassons são importantes no rastreamento de doenças e condições que podem afetar o bom andamento da gestação. Também intentou-se verificar em que medida esses exames estavam sendo oferecidos pelo hospital e/ou pelo SUS, de modo que o rastreamento se desse de forma efetiva. Com relação à eficiência, indagou-se às mulheres se elas enfrentaram demora para conseguir os exames e/ou para obter seus resultados. A análise das respostas das entrevistadas segue abaixo.

Verificou-se em relação ao público estudado que a totalidade das mulheres realizou algum tipo de exame que foi solicitado pelo seu médico assistente. Esse é um bom indicador de que o profissional se preocupou em investigar a existência de problemas que pudessem ser solucionados no decorrer do acompanhamento, sinalizando a intenção de evitar e/ou minimizar os danos deles decorrentes.

No entanto, embora o pré-natal dessas mulheres estivesse ocorrendo na maternidade estudada, foi baixo o percentual de mulheres que realizaram algum tipo de exame na instituição: apenas 32,5\%. Esse percentual pode ser explicado em parte pelo encaminhamento 
tardio ao pré-natal de alto risco do hospital e em parte pelos cortes de recursos, uma vez que a oferta de exames como as ultrassons foi um dos serviços diretamente afetados.

Apenas 37,5\% das gestantes ouvidas conseguiram realizar todos os exames solicitados às expensas do SUS. Isso significa que embora sejam solicitados os exames, as mulheres não conseguem realizá-los de forma gratuita e precisam recorrer a instituições particulares para que seu acompanhamento pré-natal não seja prejudicado. Esse achado é preocupante, pois o público que compõe a amostra é constituído majoritariamente de mulheres com baixa renda. Diante desse cenário e para as mulheres ouvidas, o rastreamento por meio de exames encontra baixa efetividade no SUS.

Com relação à eficiência, aqui entendida como a rapidez em obter exames e resultados, ou seja, reduzido tempo de espera para a realização de exames e liberação de resultados, tem-se que $62,5 \%$ das gestantes afirmou ter enfrentado demora na obtenção de exames e resultados. Embora o objetivo da pergunta fosse mensurar a eficiência relacionada a exames, esse dado não fornece uma informação clara sobre esse critério na realidade do setor público, uma vez que mais da metade das mulheres recorreu a serviços do setor privado. Outro ponto a ser considerado é que os exames de maior tempo de espera pelo SUS, as ultrassons, foram justamente os que as mulheres relataram ter feito na rede particular, ou seja, a espera foi contornada acessando serviços de instituições privadas.

Diferentemente do percentual de demora apurado - $62,5 \%$ relataram que não enfrentaram grande demora na obtenção dos exames - no decorrer das entrevistas quando era feito o aprofundamento da pergunta notou-se que há demora na obtenção de um tipo de exame usual e imprescindível na assistência obstétrica: as ultrassons. Essa é, portanto, outra falha identificada no acompanhamento das mulheres que afeta a efetividade da política pública.

\subsection{Tempo de espera pela vaga na maternidade e por atendimento no dia da consulta de pré-natal}

O tempo médio de espera por vaga na maternidade foi de 30,6 dias. Esse tempo pode ser considerado elevado em função da necessidade de realização de consultas quinzenais ou, a depender do caso, semanais, o que significa que as gestantes perdiam, em média, de duas a três consultas do pré-natal por conta da demora na alocação da vaga. Também significa tempo sem assistência profissional, o que é preocupante quando se leva em consideração se tratar de um público com alto risco de passar por complicações obstétricas, as quais representam a 
principal causa de hospitalização de mulheres em idade reprodutiva, sendo responsáveis por 26,7\% de todas as admissões (VICTORA et al, 2011).

Com relação à consulta realizada no dia da entrevista, 92,5\% das gestantes ouvidas relatou tempo de espera prolongado para ser atendida no hospital. Esse tempo de espera incluiu desde os atendimentos na recepção - que tinha a finalidade de identificação e confirmação da consulta -, na triagem feita pela enfermagem - aferição de pressão arterial, pesagem e preenchimento do cartão da gestante -, e na consulta médica propriamente dita. Consideraram ainda que é comum que esse tempo de espera seja longo e que atrasos ocorram: $60 \%$ das gestantes assim perceberam.

Foi recorrente no discurso das mulheres ouvidas atribuir a espera à falta de pontualidade dos médicos e à grande demanda por atendimento. A falta de pontualidade foi entendida como desrespeito, prejudicando o vínculo gestante-profissional e reduzindo a sensação de atendimento humanizado.

O fato de esperarem muito tempo pelo atendimento é um indicador de ineficiência dos serviços, especialmente quando se considera que são gestantes com condições de saúde que as insere em um rol específico de vulnerabilidade, cujo estresse da espera, que muitas vezes é enfrentada de pé, ou seja, sem acomodações adequadas contribui como fator desumanizante, indo de encontro aos objetivos da PNH e RC.

\subsection{Resolutividade, características do atendimento e aprovação do ambiente da maternidade pelas gestantes}

Primeiramente foi explicado que o conceito de resolutividade adotado foi o de "ter o problema ou necessidade resolvido quando recorreu ao hospital". Em seguida foi lida a frase "o atendimento no hospital e maternidade é rápido, respeitoso, acolhedor e eficiente" e perguntou-se se elas concordavam com a afirmação, oferecendo-lhes as seguintes possibilidades de resposta: concorda fortemente, concorda, indecisa, discorda e discorda fortemente. Sobre o ambiente foi questionado se elas aprovavam a estrutura oferecida pelo hospital, incluindo limpeza, conservação, existência de equipamentos, área dos consultórios, sala de vacinas, entre outros. As opções de escolha oferecidas foram: aprova fortemente, aprova, indecisa, desaprova ou desaprova fortemente. Os percentuais das respostas são apresentados abaixo.

Dentre as mulheres ouvidas, $85 \%$ entendeu que a maternidade é resolutiva porque apesar da demora elas sempre conseguiam ser consultadas pelo médico. Esse número mostra 
que apesar das dificuldades o hospital consegue eficácia nos atendimentos, pois o resultado esperado - que é realização das consultas - é atingido.

Nesse quesito, a visão das gestantes foi positiva, uma vez que as opções "concordo" e "concordo fortemente" somaram $60 \%$ das respostas. As opções relacionadas a discordância somaram $17,5 \%$ e $22,5 \%$ declararam-se indecisas, especialmente por não considerarem o atendimento rápido.

A aprovação da estrutura física também foi relatada pela imensa maioria das participantes da pesquisa: 90\% aprovaram ou aprovaram fortemente. Foi frequente mencionarem nas entrevistas que ao se tomar como referência o SUS, a estrutura do hospital é muito boa. Isso pode significar uma aprovação comparativa, ou seja, que a infraestrutura do SUS com a qual estão acostumadas se mostra malconservada ou inadequada às necessidades da população.

\subsection{Acompanhamento, eficiência e sugestões de uso dos recursos públicos}

Neste ponto das entrevistas, objetivou-se conhecer o acompanhamento feito pelas gestantes em relação ao uso de recursos públicos no hospital pesquisado, de modo a verificar três pontos: se as gestantes realizam e se gostariam de realizar algum tipo de acompanhamento da aplicação desses recursos no hospital; e na visão delas, qual seria a forma mais acessível - e por conseguinte mais transparente - de disponibilizar as informações relativas à essa parte de utilização da verba pública na realização das atividades da maternidade.

Nenhuma das gestantes ouvidas afirmou acompanhar de que forma o dinheiro da sociedade é gasto na maternidade. Isso pode significar que um quadro de apatia generalizada nos cidadãos em função das constantes notícias de casos de corrupção; que a informação financeira não está disponível para o acesso das usuárias; ou que está disponível, mas em meios de difícil acesso. Merece destaque para a questão da transparência, uma vez que os relatórios do hospital se encontram desatualizados no portal eletrônico da Prefeitura de Goiânia.

Nesse sentido, foi marcante a fala de uma das gestantes que afirmou que "Gostaria [de acompanhar], mas é muito difícil as pessoas chegar em você e falar para onde você acompanha e como você acompanha, e de qual forma" (GESTANTE № 36, entrevistada em 02/10/2017). 
Com relação ao desejo de acompanhar os gastos da instituição estudada, 70\% afirmou que teria interesse em saber como os gastos são feitos na instituição, desconstruindo, portanto, a primeira hipótese levantada - a da apatia generalizada - e reforçando as duas outras suscitadas: a informação não está disponível ou ela encontra-se disponível, mas com acesso dificultado, seja pelo meio de disponibilização, seja pela linguagem com que ela é apresentada.

O meio mais acessível para a finalidade proposta, de acordo com as respondentes, seria a televisão - aqui foram agrupadas as menções a jornal televisionado também - seguida da internet, da revista disponível na sala de espera da maternidade, do mural e do jornal impresso. Nota-se que os meios mencionados são aqueles que a gestante pode acessar remotamente ou do conforto do lar, em condições, possivelmente, de menos estresse, com menos ruído - na sala de espera do ambulatório o barulho de conversas é frequente - e mais tranquilidade para compreender o que está sendo divulgado.

\subsection{Participação das gestantes em cursos para gestantes, em avaliações, no planejamento e nas tomadas de decisões do hospital}

Neste tópico foram reunidas as perguntas do roteiro de entrevistas que tinham como finalidade obter informações que tivessem relação com autonomia e com participação social. Portanto, questionou-se as gestantes acerca do seguinte: a) se a maternidade em algum momento - seja no atendimento da recepção, seja na triagem, seja nos consultórios dos médicos - informou as gestantes sobre a existência de cursos para gestantes, oficinas sobre temas relacionados à gestação e ao parto, ou rodas de discussão acerca desses temas; b) se na maternidade elas foram convidadas a realizar algum tipo de avaliação da instituição, de modo a fornecer opinião sobre quesitos como atendimento, ambiente/infraestrutura, cursos, exames, salas de vacinas, ou quaisquer outros serviços entregues à comunidade; e c) se as gestantes consideram - tendo como ponto de partida a sua vivência pessoal com a instituição - que há abertura para a comunidade participar dos processos de planejamento e tomada de decisões na instituição pesquisada. Os percentuais de distribuição das respostas são apresentados abaixo.

Atinente à oferta de cursos, $90 \%$ das gestantes ouvidas alegaram que a elas não foram oferecidos, por parte da maternidade, cursos para gestantes, oficinas ou rodas de conversa. Apenas $10 \%$ receberam alguma informação relativa à oferta dessas atividades por parte da maternidade. 
Importante destacar que o hospital deixou de realizar esse tipo de ação educativa em função dos cortes nos repasses da Prefeitura de Goiânia. Desta maneira, o achado é coerente com a realidade vivida pela instituição e supõe-se que as mulheres que receberam alguma informação a respeito dessas atividades devem tê-la recebido antes da interrupção total dos cursos.

Os resultados mostram o impacto do problema financeiro sobre os cursos, uma vez que $90 \%$ das mulheres deixaram de ter oportunidade de deles participarem. Os cursos, oficinas e rodas de conversa para gestantes são alguns dos importantes instrumentos para prepararem as usuárias para o parto e instruí-las sobre as fases da gestação.

A oferta desses cursos promove uma maior autonomia à gestante, na medida em que as mulheres que detêm mais informações sobre seus direitos, sobre as mudanças e acontecimentos típicos da gestação e do parto e sobre as possibilidades de escolha que lhes cabem são capazes de participar de forma mais ativa das decisões relativas ao plano de parto e às condutas terapêuticas adotadas pela equipe de saúde.

No que se refere à participação em avaliações, enquanto avaliadoras, tem-se que 97,5\% das mulheres consultadas não foram convidadas a participar de alguma espécie de atividade avaliativa na maternidade e, portanto, não tiveram a oportunidade de relatar suas queixas, sugestões, elogios e vivências no decorrer do tempo em que estão sendo assistidas na instituição. Esse achado mostra que é baixa a predisposição da instituição em ouvir as usuárias.

Com relação à abertura para participação da comunidade nos processos de planejamento e tomada de decisões, a maioria das gestantes percebem que essa abertura não existe: $72,5 \%$. O sistema de participação social adotado pela instituição inclui os Comitês Gestores que contam com a participação de gestores, usuárias e profissionais de saúde. Uma vez que as usuárias desconhecem esses mecanismos de participação e não estão a par das formas de acompanhar as discussões ali geradas nota-se que os mecanismos de inclusão das usuárias não estão sendo efetivos.

\subsection{Percepção das gestantes sobre avaliação}

Neste último tópico, intentou-se verificar a existência de interesse por parte das gestantes em participar das avaliações da maternidade e a percepção que elas detêm acerca da avaliação, incluindo o que elas pensam sobre a importância de avaliar os serviços e atividades da maternidade. 
Quase que a totalidade das gestantes - 90\% - entendem que a avaliação é uma atividade importante a ser realizada pela maternidade e quando indagadas acerca da razão dessa importância, as manifestações que surgiram foram nessa linha: "É, é importante, né? Porque cada um tem a sua visão. É importante as pessoas que utilizam, né, participarem dessa... [atividade]" (GESTANTE ${ }^{\circ}$ 02, entrevistada em 03/08/2017).

Assim, 87,5\% das mulheres ouvidas respondeu que aceitaria avaliar a maternidade caso fosse convidada, demonstrando o desejo das usuárias de serem ouvidas e de contribuir para melhorias na instituição estudada.

O Quadro 2 representa o fechamento da avaliação, mostrando o que foi considerado ou não satisfatório, tendo como ponto de partida os aspectos abrangidos pela Política Nacional de Humanização e questionados às gestantes durante as entrevistas.

\begin{tabular}{|c|c|c|}
\hline Aspecto estudado & $\begin{array}{c}\text { Situação na } \\
\text { maternidade } \\
\text { estudada }\end{array}$ & Justificativa para o parecer \\
\hline $\begin{array}{l}\text { Ampliação do acesso com } \\
\text { qualidade aos serviços e } \\
\text { aos bens de saúde }\end{array}$ & Insatisfatório & $\begin{array}{l}\text { Devido ao tempo de espera por uma vaga no hospital para } \\
\text { realização do pré-natal de alto risco e à dificuldade de acesso } \\
\text { a exames como as ultrassons. }\end{array}$ \\
\hline $\begin{array}{l}\text { Ampliação do processo de } \\
\text { co-responsabilização entre } \\
\text { trabalhadores, gestores e } \\
\text { usuários nos processos de } \\
\text { gerir e de cuidar }\end{array}$ & Insatisfatório & $\begin{array}{l}\text { A deficiência no repasse de orientações às gestantes e o fato } \\
\text { de não estarem sendo realizados os cursos de gestantes } \\
\text { prejudica os processos de incremento da autonomia das } \\
\text { usuárias e de fortalecimento da responsabilização das } \\
\text { mesmas acerca de seus cuidados. }\end{array}$ \\
\hline $\begin{array}{l}\text { Fomento à pluralidade de } \\
\text { atores com participação na } \\
\text { gestão dos serviços }\end{array}$ & Insatisfatório & $\begin{array}{l}\text { Devido ao alto percentual de usuárias }-72,5 \% \text { - que não se } \\
\text { veem incluídas nos processos de planejamento e tomada de } \\
\text { decisões; e à questão da transparência na instituição: } \\
\text { indisponibilidade dos relatórios mais recentes da gestão, } \\
\text { dificultando o exercício do controle social. }\end{array}$ \\
\hline $\begin{array}{l}\text { Fortalecimento do vínculo } \\
\text { com os usuários }\end{array}$ & Satisfatório & $\begin{array}{l}\text { A grande maioria das gestantes relataram se sentir à vontade } \\
\text { com a equipe de saúde e ressaltou o bom atendimento } \\
\text { recebido pelos profissionais como um aspecto positivo da } \\
\text { maternidade. }\end{array}$ \\
\hline $\begin{array}{l}\text { Ruptura com modelos de } \\
\text { gestão centralizados e } \\
\text { verticais }\end{array}$ & Insatisfatório & $\begin{array}{l}\text { Embora a maternidade possua um Conselho gestor com } \\
\text { participação de representantes da gestão, dos trabalhadores e } \\
\text { dos usuários, suas atribuições são consultivas e não } \\
\text { deliberativas. As decisões são tomadas pelo Colegiado } \\
\text { Gestor, uma outra instância cuja composição não é } \\
\text { representativa. Ademais, os usuários não percebem que há } \\
\text { abertura para participação nas decisões. }\end{array}$ \\
\hline $\begin{array}{l}\text { Otimização da ambiência } \\
\text { para favorecer o processo } \\
\text { de humanização, tanto no } \\
\text { que diz respeito ao } \\
\text { atendimento quanto com } \\
\text { relação aos processos de } \\
\text { trabalho }\end{array}$ & Satisfatório & $\begin{array}{l}\text { A maioria das gestantes aprovou o ambiente da maternidade. } \\
\text { Há ressalvas com relação à emergência, em que ocorre o } \\
\text { atendimento de pré-parto em uma sala de observação, sem o } \\
\text { preparo adequado do ambiente para o momento; com relação } \\
\text { ao número de assentos nas salas de espera por atendimento; e } \\
\text { temperatura dos ambientes. }\end{array}$ \\
\hline $\begin{array}{l}\text { Resolutividade da } \\
\text { assistência }\end{array}$ & Satisfatório & $\begin{array}{l}\text { A resolutividade foi avaliada e aprovada por } 85 \% \text { das } \\
\text { gestantes. }\end{array}$ \\
\hline
\end{tabular}


A apreciação do Quadro 2 mostra que, sob o ponto de vista das usuárias, há quatro pontos que necessitam de melhorias por parte da gestão local, a fim de que a PNH possa ter seus resultados de acordo com seus propósitos e se consolidar no contexto da Rede Cegonha, mais especificamente na instituição pesquisada. Eles estão relacionados com o acesso a serviços e participação social nos processos de gestão. Isso significa dizer que é necessário haver na instituição um movimento em direção à inclusão, tanto no que se refere a oportunidade de obter o atendimento e os exames de que necessitam, quanto no que refere ao aprimoramento dos processos e mecanismos de escuta e de horizontalização da gestão.

\section{CONCLUSÃO}

O estudo buscou avaliar a Política Nacional de Humanização em uma maternidade da rede municipal de saúde de Goiânia/GO.

Como fruto da avaliação, três aspectos foram considerados satisfatórios resolutividade da assistência, otimização da ambiência e fortalecimento do vínculo com os usuários - e quatro foram considerados insatisfatórios - ruptura com modelos de gestão centralizados e verticais, fomento à pluralidade, ampliação do acesso aos serviços e ampliação do processo de co-responsabilização entre os atores.

Conclui-se que a maternidade apresenta aspectos positivos com relação ao atendimento e à infraestrutura. De modo geral, as gestantes se sentiram acolhidas e bem tratadas pela equipe de saúde.

Entretanto, ainda há um caminho a ser percorrido para que as mudanças preconizadas pela $\mathrm{PNH}$, tanto no que se refere a gestão quanto no que se refere ao cuidado, possam ser efetivadas. Nesse sentido, a maternidade necessita promover uma maior inclusão das usuárias nos processos de planejamento, tomada de decisões e avaliação, aprimorando e fomentando mecanismos de transparência e de escuta para que se promova uma gestão menos verticalizada e centralizadora.

Outrossim, a disseminação das informações faz-se primordial para o incremento da autonomia das usuárias e para uma interação menos médico-centrada.

\section{AGRADECIMENTOS}

Agradecemos a Fundação de Amparo à Pesquisa do Estado de Goiás (FAPEG) pelo auxílio financeiro na forma de bolsa de mestrado. 


\title{
EVALUATION OF THE NATIONAL HUMANIZATION POLICY: THE USERS' POINT OF VIEW OF A MATERNITY OF GOIANA CAPITAL WICH INTEGRATES THE STORK NETWORK
}

\begin{abstract}
The National Humanization Policy (HNP) in the context of the Stork Network (SN) proposes the transformation of the management and care carried out in the member institutions. This aims to reduce maternal and infant mortality rates, to provide users a comprehensive and dignified care experience and a more participatory and horizontal management. In this sense, the present study aimed to hold an evaluation of HNP in a maternity unit of the municipal health network of Goiânia / GO, which integrates the SN, and from the point of view of users of the institution's services. The research was applied in nature with a qualitative and descriptive approach. Forty pregnant women who were performing prenatal care in the maternity ward, from August, $03^{\text {rd }}$ of 2017 to October, $03^{\text {rd }}$ of 2017 were interviewed. They expressed their opinion about the specific items discussed in the research. As results, it was observed that four of the evaluated items were considered unsatisfactory and three were satisfactory. It was noticed that the pregnant women were satisfied with the service regarding to the cordiality of the health professionals, however they were not satisfied in relation to the waiting time to be consulted. Besides, they considered the environment of maternity adequate compared to other SUS institutions. On the other hand, some aspects were evaluated negatively they are: the disclosure of information by health professionals, the transparency in disclosure of accounts and maternity reports, the openness for community participation in planning and decision making regarding maternity management. It was concluded that the humanization in the maternity still needs actions in order to promote changes in the management which allows a greater participation of the users; and actions which provide greater autonomy to the users, especially with regard to obtaining important information for self-care and adopting a more active stance in the health-disease process.
\end{abstract}

Keywords: Evaluation of Public Policies. Humanization. Stork Network. Health Management.

\section{REFERÊNCIAS}

ALENCAR, Maria da Glória Pinto. Em busca de referências conceituais para entender a avaliação de impacto. Revista de Políticas Públicas, São Luís, v. 17, n. 1, p. 81-90, jan./jun. 2013. Disponível em: http://www.redalyc.org/html/3211/321131081008/. Acesso em: 11 jun. 2016.

BRASIL. Ministério da Saúde. Secretaria de Atenção à Saúde. Núcleo Técnico da Política Nacional de Humanização. HumanizaSUS: documento base para gestores e trabalhadores do SUS. 4. ed. Brasília: Ministério da Saúde, 2008.

CAVALCANTI, Mônica Maria de Arruda. Avaliação de políticas públicas e programas governamentais - uma abordagem conceitual. Interfaces de Saberes, Caruaru, v. 6, n. 1, 2006. Disponível em: 
http://www.socialiris.org/antigo/imagem/boletim/arq48975df171def.pdf. Acesso em: 25 jun. 2017.

CAVALCANTI, Paula Arcoverde. Sistematizando e comparando os enfoques de avaliação e de análise de políticas públicas: uma contribuição para a área educacional. 2007. $301 \mathrm{f}$. Tese (Doutorado em Educação) - Programa de Pós-Graduação em Educação, Universidade Estadual de Campinas, Campinas, 2007.

CUNHA, Carla Giane Soares da. Avaliação de Políticas Públicas e Programas

Governamentais: tendências recentes e experiências no Brasil. Secretaria de Coordenação e Planejamento/RS, 2006.

GIL, Antônio Carlos. Métodos e técnicas de pesquisa social. 6. ed. São Paulo: Atlas, 2008.

HÖFLING, Eloisa de. Estado e políticas (públicas) sociais. Cadernos Cedes, v. 21, n. 55, p. 30-41, 2001. Disponível em: http://www.scielo.br/pdf/ccedes/v21n55/5539. Acesso em: 23 maio 2016.

INSTITUTO TRATA BRASIL. Situação Saneamento no Brasil. São Paulo, 2018.

Disponível em: http://www.tratabrasil.org.br/saneamento-no-brasil. Acesso em: 12 jan. 2018.

MARTES, Ana Cristina Braga et al. Modelo de avaliação de programas sociais prioritários. Relatório final. Programa de apoio à gestão social no Brasil. Campinas: NEPP/UNICAMP, 1999.

MINAS GERAIS. Assembleia Legislativa de Minas Gerais. A Assembleia Legislativa de Minas Gerais no ciclo de políticas públicas. 2016. Disponível em:

https://politicaspublicas.almg.gov.br/sobre/index.html\#A_ALMG_no_ciclo_de_politicas_pub licas. Acesso em: 23 mar. 2017.

ORGANIZAÇÃO DAS NAÇÕES UNIDAS. Objetivos do Milênio. [201-?]. Disponível em: http://www.objetivosdomilenio.org.br/gestantes/. Acesso em: 23 mar. 2017.

RAMOS, Marília Patta; SCHABBACH, Letícia Maria. O estado da arte da avaliação de políticas públicas: conceituação e exemplos de avaliação no Brasil. Revista de Administração Pública, Rio de Janeiro, v. 46, n. 5, p. 1271-1294, 2012. Disponível em: http://www.scielo.br/pdf/rap/v46n5/a05v46n5. Acesso em: 17 jan. 2017.

RUA, Maria das Graças. Políticas públicas. Florianópolis: CAPES, 2009.

SECCHI, Leonardo. Políticas Públicas: conceitos, esquemas de análise, casos práticos. São Paulo: Cengage Learning, 2010.

SERAFIM, Milena Pavan; DIAS, Rafael de Brito. Análise de política: uma revisão da literatura. Cadernos Gestão Social, Salvador, v. 3, n. 1, p. 121-134, 2012. Disponível em: 
http://www.periodicos.adm.ufba.br/index.php/cgs/article/view/213/pdf_22. Acesso em: 15 maio 2017.

SILVA, André Ricardo Batista de Barros E. Avaliação de políticas públicas: estudo do comportamento de indicadores relacionados com a saúde em municípios do estado de Pernambuco após a emenda Constitucional No 29. 2008. 156 f. Dissertação (Mestrado em Administração) - Escola Brasileira de Administração Pública e de Empresas, Fundação Getúlio Vargas, Rio de Janeiro, 2008.

SIMÕES, Armando A. Avaliação de programas e políticas públicas. Programa de aperfeiçoamento para carreiras 2015 da Escola Nacional de Administração Pública (Enap). Disponível em: file:///C:/Users/Claudia/Downloads/AVALIACAO-DE-PROGRAMAS-EPOLITICAS-PUBLICAS-003.pdf. Acesso em: 20 jul. 2018.

SOUZA, Celina. Políticas públicas: uma revisão da literatura. Sociologias, Porto Alegre, v. 8, n. 16, p. 20-45, 2006. Disponível em: http://www.scielo.br/pdf/soc/n16/a03n16. Acesso em: 21 abr. 2016.

TINÔCO, Dinah dos Santos; SOUZA, Lincoln Moraes de; OLIVEIRA, Alba Barbosa de. Avaliação de políticas públicas: modelos tradicional e pluralista. Revista Políticas Públicas, São Luís, v. 15, n. 2, p. 305-313, 2012. Disponível em: http://www.periodicoseletronicos.ufma.br/index.php/rppublica/article/view/847. Acesso em: 10 abr. 2017.

VICTORA, Cesar G. et al. Saúde de mães e crianças no Brasil: progressos e desafios. The Lancet, London, p. 32-46, 2011. Disponível em: http://download.thelancet.com/flatcontentassets/pdfs/brazil/brazilpor2.pdf. Acesso em: 17 fev. 2018.

\section{DADOS DOS AUTORES}

\section{Mirian Castro Portilho Dias Amorim}

E-mail: mirinhadias86@gmail.com

Currículo Lattes: http://lattes.cnpq.br/9086250975091449

Mestrado em Administração Pública, especialista em Gestão da Saúde e graduada em Enfermagem pela Universidade Federal de Goiás (UFG), tendo como temas de pesquisa políticas públicas de saúde e gestão de saúde. Durante a graduação participou de Projetos de Extensão na área de Empoderamento de Famílias e Enfrentamento de Violência contra a Mulher e na área de Busca de Ativa de Sintomáticos Respiratórios. É. Atualmente é servidora técnico-administrativa na UFG.

\section{Cláudia Regina Rosal Carvalho}

E-mail: clregina@hotmail.com

Currículo Lattes: http://lattes.cnpq.br/4883069832734425

Doutorado em Ciências Ambientais pela Universidade Federal de Goiás (UFG), mestrado em Economia pela Universidade Federal de Uberlândia (UFU) e graduação em Ciências Econômicas pela UFU. Atualmente é professora associada da UFG. Tem experiência na área 
AMORIM, M. C. P D.; CARVALHO, C. R. R. Avaliação da política nacional de humanização: o ponto de vista das usuárias de uma maternidade da capital goiana integrante da rede Cegonha

de Economia, com ênfase em Economia Política e Desenvolvimento Regional atuando principalmente nos seguintes temas: Economia Política, História Econômica, Economia Brasileira, Desenvolvimento Econômico Regional, Ciências Ambientais e Formulação de Políticas Públicas. 